\title{
Sensitivity of aerosol optical thickness and aerosol direct radiative effect to relative humidity
}

\author{
H. Bian ${ }^{1,2}$, M. Chin ${ }^{2}$, J. M. Rodriguez ${ }^{2}$, H. Yu ${ }^{1,3}$, J. E. Penner ${ }^{4}$, and S. Strahan ${ }^{1,2}$ \\ ${ }^{1}$ Goddard Earth Sciences and Technology Center, University of Maryland, Baltimore County, Baltimore, Maryland, USA \\ ${ }^{2}$ Atmospheric Chemistry and Dynamics Branch, NASA Goddard Space Flight Center, Greenbelt, Maryland, USA \\ ${ }^{3}$ Climate and Radiation Branch, NASA Goddard Space Flight Center, Greenbelt, MD, USA \\ ${ }^{4}$ Dept. of Atmospheric, Oceanic and Space Sciences, University of Michigan, Ann Arbor, Michigan, USA
}

Received: 20 February 2008 - Published in Atmos. Chem. Phys. Discuss.: 11 July 2008

Revised: 6 November 2008 - Accepted: 24 March 2009 - Published: 2 April 2009

\begin{abstract}
We present a sensitivity study of the effects of spatial and temporal resolution of atmospheric relative humidity (RH) on calculated aerosol optical thickness (AOT) and the aerosol direct radiative effects (DRE) in a global model. We carry out different modeling experiments using the same aerosol fields simulated in the Global Modeling Initiative (GMI) model at a resolution of $2^{\circ}$ latitude by $2.5^{\circ}$ longitude, using time-averaged fields archived every three hours by the Goddard Earth Observation System Version 4 (GEOS4), but we change the horizontal and temporal resolution of the relative humidity fields. We find that, on a global average, the AOT calculated using $\mathrm{RH}$ at a $1^{\circ} \times 1.25^{\circ}$ horizontal resolution is $11 \%$ higher than that using $\mathrm{RH}$ at a $2^{\circ} \times 2.5^{\circ}$ resolution, and the corresponding DRE at the top of the atmosphere is $8-9 \%$ and $15 \%$ more negative (i.e., more cooling) for total aerosols and anthropogenic aerosol alone, respectively, in the finer spatial resolution case. The difference is largest over surface escarpment regions (e.g. $>200 \%$ over the Andes Mountains) where RH varies substantially with surface terrain. The largest zonal mean AOT difference occurs at $50-60^{\circ} \mathrm{N}(16-21 \%)$, where AOT is also relatively larger. A similar impact is also found when the time resolution of $\mathrm{RH}$ is increased. This increase of AOT and aerosol cooling with the increase of model resolution is due to the highly non-linear relationship between $\mathrm{RH}$ and the aerosol mass extinction efficiency (MEE) at high RH (>80\%). Our study is a specific example of the uncertainty in model results highlighted by multi-model comparisons such as AeroCom, and points out one of the many inter-model differences that can contribute to the overall spread among models.
\end{abstract}

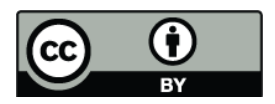

Correspondence to: H. Bian (huisheng.bian@nasa.gov)

\section{Introduction}

Relative humidity (RH) can significantly influence ambient aerosol optical thickness (AOT) and, therefore, aerosol direct radiative forcing (Kinne et al., 2003; Malm et al., 2005; Pahlow et al., 2006; Wang et al., 2008). For example, the AOT at $550 \mathrm{~nm}$ measured during ACE-Asia was tripled when the RH increased from 50\% to $95 \%$ (Yoon and Kim, 2006). Accounting for the impact of RH on AOT in chemistry transport model (CTM) simulations requires a good simulation of moisture field by the underlying General Circulation Model (GCM) and consideration of spatial and temporal resolution of the RH field because this field exhibits large heterogeneity in both space and time. This issue of RH representation is directly relevant to the work of AeroCom (Aerosol Comparison between Observations and Models), a model intercomparison effort to assess aerosol properties and their atmospheric effects, which includes models with different spatial resolutions (Kinne et al., 2006; Schulz et al., 2006; Textor et al., 2006). For example, the horizontal resolutions range from $1.1^{\circ}$ latitude $\times 1.1^{\circ}$ longitude to $10^{\circ} \times 22.5^{\circ}$ in 20 models involved in the assessment of multi-model optical properties by Kinne et al. (2006).

Since the aerosol optical thickness (AOT) is determined by the product of aerosol dry mass and the mass extinction efficiency (MEE), a non-linear relationship between MEE and RH will translate into non-linearity in AOT and a dependence on the RH resolution used in the model. Figure 1 shows the change of MEE of sea salt particles (left) and internally mixed fossil fuel particles (right) as a function of RH. The figure indicates that the change of aerosol MEE with RH is highly non-linear for $\mathrm{RH}>80 \%$. Due to this non-linear relationship, the sub-grid RH variation will inevitably yield difference among AOTs which are calculated using different spatial (or temporal) averages for RHs, even if the RHs originate from the same GCM.

Published by Copernicus Publications on behalf of the European Geosciences Union. 

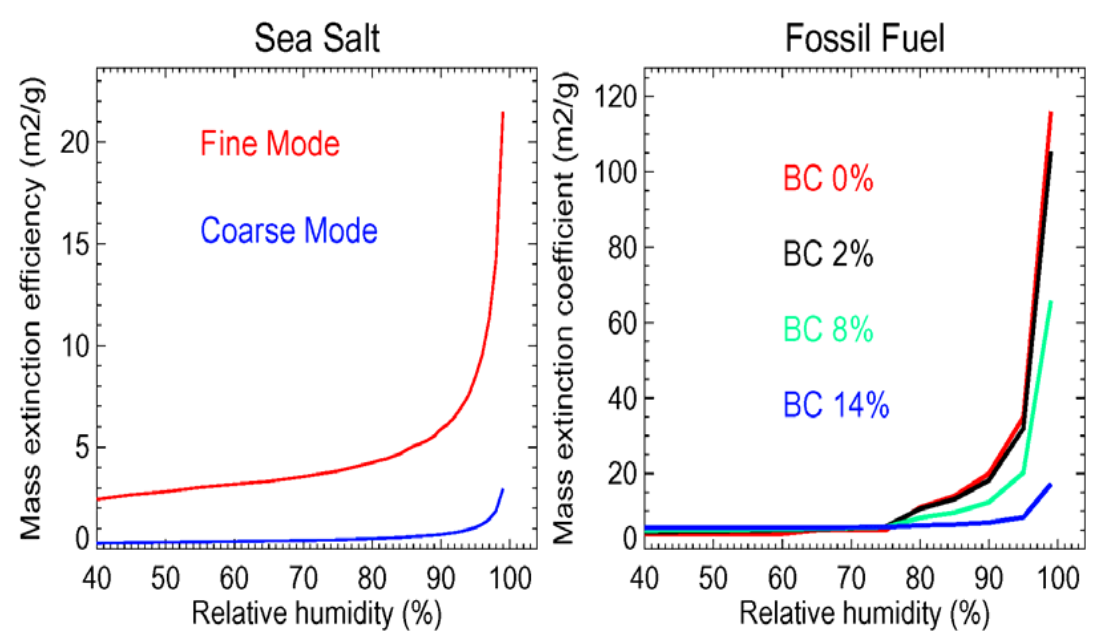

Fig. 1. Mass extinction efficiencies (at $\lambda=550 \mathrm{~nm}$ ) of sea salt particles (left) and fossil fuel particles (right) as a function of relative humidity. Fossil fuel aerosol contains internally mixed sulfate, black carbon, and organic carbon. Four color lines in the right are associated with four aerosol compositions with different BC fractions. MEEs are calculated by Mie-theory with the basic information of aerosol size distribution and refractive index.

Table 1. Horizontal and temporal resolutions of RH used in the three experiments ${ }^{1}$.

\begin{tabular}{lll}
\hline Experiments & $\begin{array}{l}\text { Horizontal resolution }^{2} \\
\text { (latitude } \times \text { longitude) }\end{array}$ & $\begin{array}{l}\text { RH temporal } \\
\text { averaging period } \\
\text { (hours) }\end{array}$ \\
\hline LSHT & $2^{\circ} \times 2.5^{\circ 3}$ & 3 \\
HSHT & $1^{\circ} \times 1.25^{\circ}$ & 3 \\
LSLT & $2^{\circ} \times 2.5^{\circ}$ & 6 \\
\hline
\end{tabular}

1 all experiments use GMI aerosol mass with spatial resolution $2^{\circ} \times 2.5^{\circ}$

2 all experiments have 42 vertical layers to top lid at $0.01 \mathrm{mb}$

${ }^{3} \mathrm{RH}$ averaged from $1^{\circ} \times 1.25^{\circ}$.

The objective of this paper is to investigate the potential AOT changes arising solely from adopting different $\mathrm{RH}$ spatial and temporal resolutions in global models. We will address this issue utilizing a common global model framework and utilizing the same set of aerosol mass distribution for the different components simulated in the model. Specifically, we will answer: 1.) What are the calculated AOT changes if we adopt $\mathrm{RH}$ at two typical spatial resolutions (i.e. $1^{\circ}$ latitude $\times 1.25^{\circ}$ longitude and $\left.2^{\circ} \times 2.5^{\circ}\right)$ and for two typical RH time-averaging intervals (i.e. 3-h and 6-h)? 2.) Where and when is the AOT most sensitive to the different resolutions of RH? The resolutions chosen (Table 1) are the most common ones used in the current models, for example, 13 out of 20 models evaluated by Kinne et al. (2006) have a horizontal resolution close to $2^{\circ} \times 2.5^{\circ}$. In addition, we will use a radiative transfer model to examine the variations of aerosol direct radiative effect (DRE) at the top of atmospheric (TOA) due to the AOT results from different resolutions to give an overall estimation of the effect on climate.

An analogous idealized study of the impact of sub-grid variations of RH on the direct radiative forcing (DRF) of sulfate aerosol (i.e., the difference in DRE with and without sulfate aerosols) using a limited_area_model was presented by Haywood et al., 1997. The study found that the estimated DRF using a low resolution model $(160 \mathrm{~km}$ by $160 \mathrm{~km})$ was approximately $73 \%$ and $60 \%$ lower than that using a high resolution model ( $2 \mathrm{~km}$ by $2 \mathrm{~km}$ ) for clear sky and cloudy sky, respectively.

In Sect. 2 we first describe the models used in this study and the three sensitivity experiments. In Sect. 3 we then show the results of model AOT calculated at different spatial and temporal resolutions and discuss reasons for those differences in Sect. 3.1 to 3.4. The corresponding changes of DRE are shown in Sect. 3.5. Finally the conclusions and implications of the study are given in Sect. 4.

\section{Model description and experiment design}

\subsection{GMI aerosol module}

The Global Modeling Initiative (GMI) model is a modular 3D CTM that can be used to assess the impact of various natural and anthropogenic perturbations on atmospheric composition and chemistry (e.g., Strahan and Douglass et al., 2004; Strahan et al., 2007; Considine et al., 2004; Douglass et al., 2004; Liu et al., 2007). The GMI CTM can be driven by different meteorological fields(Liu et al.,2007). In this study, we use the assimilated meteorological fields from NASA's 
Goddard Earth Observation System Version 4 (GEOS-4) data assimilation system (DAS) (Bloom et al., 2005). The original GEOS-4 DAS fields have a spatial resolution of $1^{\circ}$ latitude, $1.25^{\circ}$ longitude, and 55 vertical layers with a top lid at 0.01 $\mathrm{mb}$, but they are degraded to $2^{\circ}$ latitude, $2.5^{\circ}$ longitude, and 42 vertical layers (reduced layers in stratosphere) for GMI simulations. The GEOS-4 DAS meteorological fields are archived once every $3 \mathrm{~h}$.

The general physical and chemical processes for aerosols in GMI CTM have been described by Liu et al., 2007. The model simulates aerosol mass distribution for sulfate, black carbon, organic carbon, dust, and sea salt. Instead of using the prescribed emissions in Liu et al., 2007, in this study, the dust and sea-salt emissions are calculated in GMI with the emission algorithms from the Goddard Chemistry Aerosol Radiation and Transport (GOCART) model (Ginoux et al., 2001; Chin et al., 2002, 2004). Briefly, dust emission rates of eight size groups $(0.1-10 \mu \mathrm{m})$ are calculated as a function of surface topographic depression, surface type, 10-m wind speed, and surface wetness (Ginoux et al., 2001); sea salt emissions for 4 size groups $(0.1-10 \mu \mathrm{m})$ are calculated as a function of surface wind speed (Monahan et al., 1986; Gong et al., 1997, 2003). A lognormal size distribution is assumed for each dust and sea salt bin (Table 2 in Chin et al., 2002). Aerosols originating from fossil fuel are assumed to be internally mixed for AOT calculations, as are aerosols from biomass burning, with compositions assumed to be in the ratio of the calculated mass distributions for the different components. All other aerosols are externally mixed. The size distributions of the internally mixed aerosols are calculated for a single size group, with distribution parameters taken from Table 5.1 of IPCC 2001: for fossil fuel aerosol the modal radius is $0.05 \mu \mathrm{m}$ and the geometric standard deviation is 1.9 , and for biomass burning aerosol the modal radius is 0.08 um and the geometric standard deviation is 1.65. Natural sulfate aerosol was assumed to follow the size distribution given by Chuang et al. (1997) and natural organic matter (OM) was based on measurements by Radke et al. (1988). The hygroscopic growth factors of sea salt are compiled based on the databases of Optical Properties of Aerosol and Clouds (OPAC) (Hess et al., 1998). The hygroscopic growth factors for other aerosol particles except dust are calculated based on Kohler theory (Penner et al., 1998). The refractive index of internally mixed aerosols is determined by volume weighted refractive indices of the individual aerosols.

Three aerosol optical properties (AOT, single scattering albedo $(\omega)$, and asymmetry factor $(g)$ ) were calculated for the radiative transfer simulation. MEEs, which directly determine AOT, are calculated by Mie scattering theory for each of the particle types, i.e. each of the eight dust bin sizes, fine mode and coarse mode of sea salt, internally mixed fossil fuel particle, internally mixed biomass burning particle, natural sulfate, and natural $\mathrm{OM}$, using the corresponding size distribution and complex refractive index of each particle type as described above. AOT, $\omega$, and g of aerosols are RH dependent except for dust and the quantities also have a wavelength dependence which is necessary to account for the effect of the whole shortwave spectrum for DRE. However, only AOT at $550 \mathrm{~nm}$ is used in the AOT-RH analyses. The calculated aerosol MEE is tabulated as a function of aerosol types, relative humidity, size bins, and the mass fraction of BC (for internally mixed fossil fuel and biomass burning aerosols). The MEEs are tabulated at $21 \mathrm{RH}$ levels starting at 0 with an increment of $5 \%$ except the last level, which is $99 \%$. The MEEs were linearly interpolated at other RHs less than $99 \%$. Between RH of $99 \%$ and $100 \%$, MEEs were linearly extrapolated.

\subsection{Radiative transfer model}

The aerosol direct effect on solar radiation is calculated with the Goddard Space Flight Center radiative transfer model (Chou and Suarez, 1999; Chin et al., 2001; Weaver et al., 2001). This model accounts for absorption by $\mathrm{O}_{3}, \mathrm{CO}_{2}, \mathrm{O}_{2}$, $\mathrm{H}_{2} \mathrm{O}$, and aerosols, and includes for scattering by clouds, aerosols, and gases. The solar spectrum $(0.2$ to $10 \mu \mathrm{m})$ is divided into eight bands in the UV and visible range and three bands in the near infrared. The ozone fields are the climatology distributions from Logan et al. (1999), and satellite retrieval of SBUV for the stratosphere (Fishman et al., 2003). A global constant $\mathrm{CO}_{2}$ mixing ratio of $350 \mathrm{ppm}$ is used. Three aerosol optical properties described in Sect. 2.1 determine the aerosol radiative effect. The water vapor, cloud fields, as well as temperature and surface albedo are taken from the GEOS-4 DAS.

\subsection{Model experiments}

The GMI aerosol module was first used to calculate mass distributions for the different aerosol types, at a spatial resolution of $2^{\circ} \times 2.5^{\circ}$, and temporal resolution of three hours. As described in Liu et al., 2007, the calculations utilized offline fields of $\mathrm{OH}, \mathrm{HO}_{2}$ and $\mathrm{O}_{3}$ calculated by the GMI gasphase model with the same meteorological fields. Gas-phase concentrations of $\mathrm{H}_{2} \mathrm{O}_{2}$ are recalculated within the aerosol module to account for the impact of $\mathrm{SO}_{2}$ in-cloud oxidation.

We performed three experiments (Table 1) to investigate the differences in model calculated AOT and aerosol DRE resulting from the use of different spatial and temporal resolutions of the RH field. In all three experiments, the RH was obtained from the GEOS-4 DAS, and the GMI simulated aerosol mass was unchanged in order to highlight the AOT change solely due to the RH resolution change.

We first calculated AOT using the RH at the typical GMI model resolution, which is $2^{\circ}$ latitude by $2.5^{\circ}$ longitude with 42 vertical layers, and uses archived meteorological fields averaged every $3 \mathrm{~h}$. In this case, the RH fields have been degraded from the original GEOS-4 DAS $1^{\circ} \times 1.25^{\circ} \times 55$ level resolution. We denote this calculation as the case 
Table 2. The correlation (R), bias (B), and root mean square error (E) between GMI and MODIS and between GMI and MISR over land and ocean regions.

\begin{tabular}{lllllll}
\hline & \multicolumn{3}{c}{ GMI vs. MODIS } & \multicolumn{4}{c}{ GMI vs. MISR } \\
\hline & R & B & E & R & B & E \\
Land & 0.60 & 0.79 & 0.17 & 0.47 & 0.89 & 0.21 \\
Ocean & 0.66 & 0.78 & 0.09 & 0.52 & 0.69 & 0.13 \\
\hline
\end{tabular}

LSHT (means Low horizontal Spatial resolution and High Temporal resolution).

We then conducted two sensitivity studies, each differing from LSHT in horizontal (HSHT) or temporal resolution (LSLT): in the first one, the horizontal resolution of the RH was increased to the original GEOS-4 DAS resolution of $1^{\circ} \times 1.25^{\circ}$ (a factor of 4 increase of spatial resolution), while in the second case, the RH meteorological update frequency was decreased from the 3-h average in LSHT to a 6-h average (a factor of 2 decrease of temporal resolution).

All experiments are run for one and half years (1 July 2000-31 December 2001) with the first half year used for spin up.

\section{Results}

In this section, we first compare the AOT simulation in the case of LSHT to satellite and ground based data (Figs. 2 and 3). This is not intended as an exhaustive testing of the model results, but rather to show that our base calculations are reasonable when compared to observations. We then present and discuss the relationship between AOT and RH in terms of the change in the RH horizontal and temporal resolution.

\subsection{The AOT simulation in the case of LSHT}

The LSHT AOT from the GMI model is compared with satellite measurements from Moderate-resolution Imaging Spectroradiometer (MODIS) and Multi-angle Imaging Spectroradiometer (MISR) for April 2001 (Fig. 2) and the corresponding statistical analyses of the correlation $(\mathrm{R})$, the relative bias (B), and the root mean square error (E) over land and ocean regions are given in Table 2. The relative bias (B) is defined as a ratio of the averaged model AOT versus the averaged measured AOT over grid boxes where the observation exists. Overall, the GMI captures the main features of the observed AOT apart from the Americas (Fig. 2). For example, both model and satellite data show very high AOTs over Southeast Asia and East Asia. This is because April is the month with high biomass burning emission over Southeast Asia and with high dust events over East Asia along Taklimakan, Mongolia, and the Gobi regions. The industrial
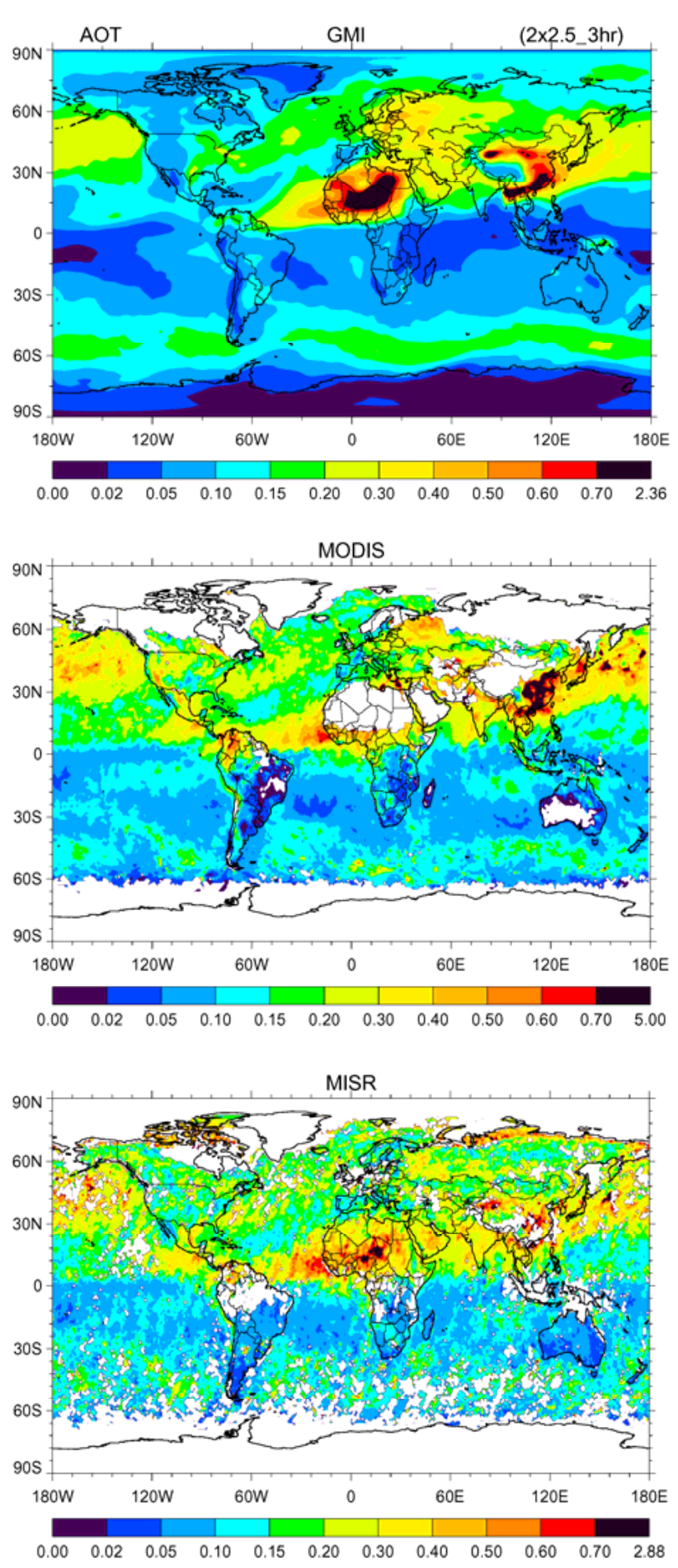

Fig. 2. Aerosol Optical Thickness (AOT) at $550 \mathrm{~nm}$ in April 2001 from GMI LSHT simulation (upper panel) and satellite measurements of MODIS (middle panel) and MISR (lower-panel). Note that the model monthly mean is not filtered for the presence of satellite data. 

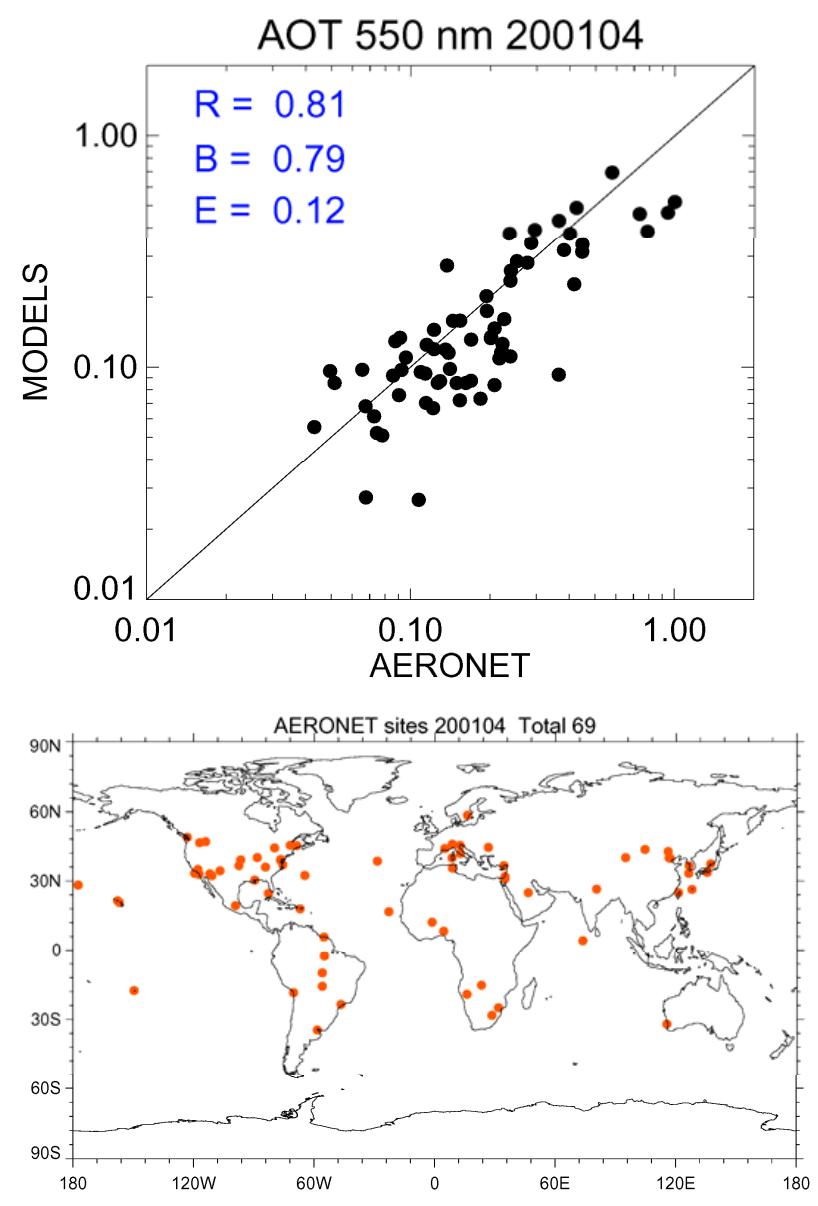

Fig. 3. Comparison of AOT $(550 \mathrm{~nm})$ monthly mean between GMI LSHT simulation and AERONET measurement (upper panel) over 69 sites (lower panel) in April 2001. R, B, and E are the correlation, the relative bias, and the root mean square error between model and measurement.

pollutant also contributes the high AOT over East Asia. The other high AOTs are evident over polluted land areas such as Western Europe and Eastern North America and over the deserts such as in Western Africa, as well as downwind from these regions. The lowest AOT occurs in southern hemisphere $(\mathrm{SH})$ tropical regions. Overall, the modeled AOT is generally lower than satellite observations over most remote oceans (Table 2).

The LSHT AOT from the GMI model is also compared with available Aerosol Robotic Network (AERONET) measurements in April 2001 in Fig. 3. The statistical analysis is given at all stations since there are very few AERONET oceanic stations. Overall, model AOTs have better agreement with AERONET results. The correlation of the two datasets $(\mathrm{R}=0.81)$ is much higher than those shown in Table 2. The absolute difference $(\mathrm{E}=0.12)$ is less than those from model-satellite comparisons over land. However, the relative bias (B) indicates that the model AOT is also lower
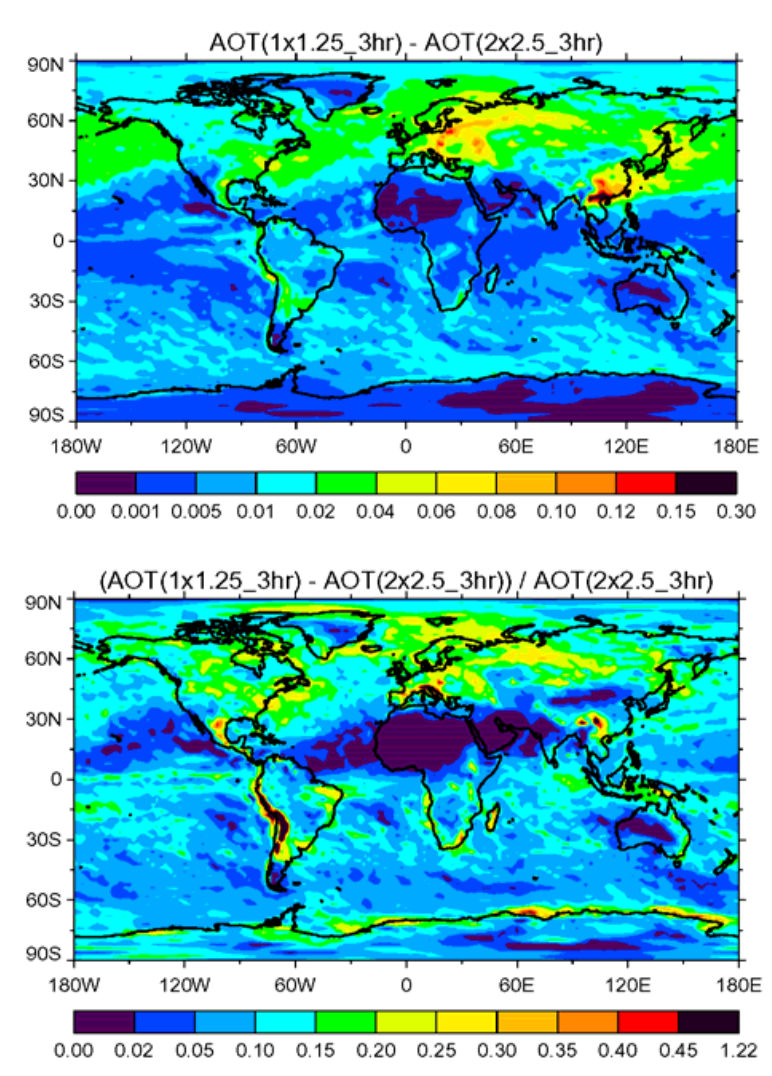

Fig. 4. Absolute (upper-panel) and relative (lower-panel) monthly mean AOT differences in April 2001 when using RH horizontal resolution of $1^{\circ} \times 1.25^{\circ}$ versus $2^{\circ} \times 2.5^{\circ}$.

than AERONET measurements $(\mathrm{B}=0.79)$. Considering that the model oceanic AOT is lower than that of satellites, the calculated bias with respect to AERONET might be reduced even more if more ocean station measurements were available. Model spatial resolution may contribute to the AOT underestimation in the LSHT simulation.

\subsection{The effect of the change $\mathrm{RH}$ horizontal resolution on AOT}

Monthly mean AOT differences associated with the change of RH horizontal resolution for April 2001 are shown in Fig. 4. The upper panel of the figure shows the absolute difference [AOT(HSHT)-AOT(LSHT)] and the lower panel shows the relative difference [(AOT(HSHT)AOT(LSHT))/AOT(LSHT)]. The figure shows that regional AOT is sensitive to the choice of the two prescribed RH horizontal resolutions (Table 1). The highest AOT differences generally occur over regions with high hygroscopic aerosol loading, such as $\mathrm{NH}$ middle latitudes, or in regions with sharp RH spatial gradients, such as land/ocean boundaries and surface escarpments. The AOT change is particularly sensitive 

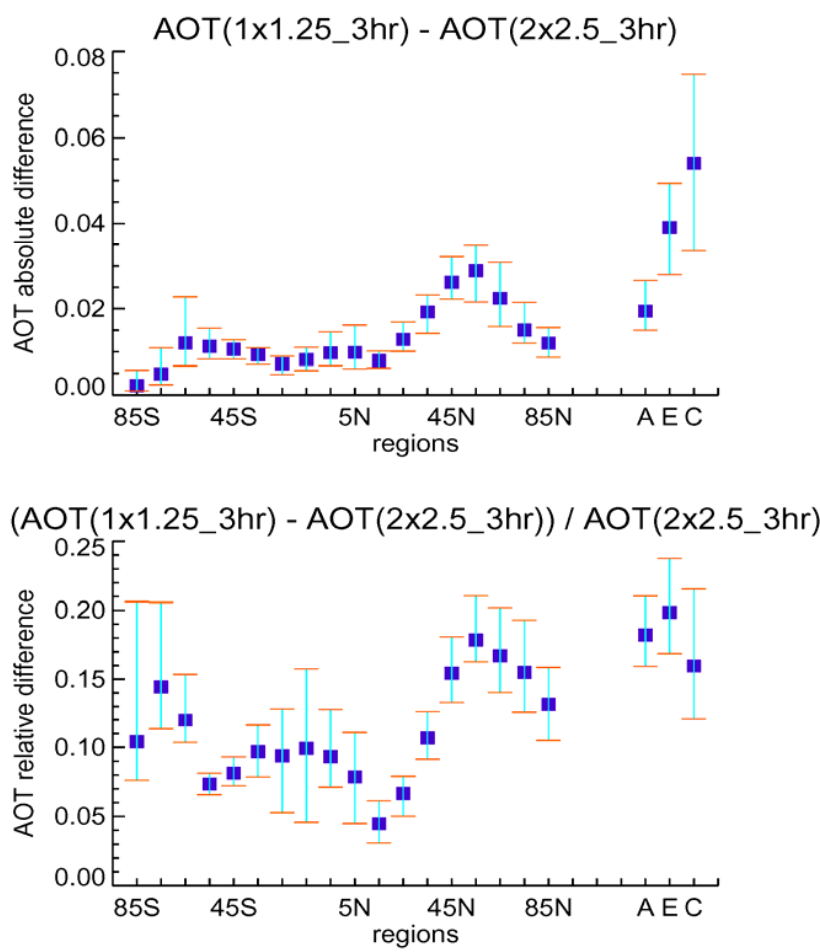

Fig. 5. Zonal mean AOT absolute (upper panel) and relative (lower panel) changes in every $10^{\circ}$ latitude between two cases with different RH horizontal resolutions. Blue squares are annual averaged values. The vertical bars represent the full range of seasonal variations during 2001. On the far right are regional data for Eastern America (A), Western Europe (E), and Eastern China (C).

to the last case; for example, the relative difference is typically more than $200 \%$ over the Andes Mountains.

This figure reveals that the AOT is always enhanced when the RH horizontal resolution is increased. The numerical reason behind this is the non-linear relationship between AOT and RH (Fig. 1). The method of calculating AOT using sub-grid RH first and then averaging will always yield a higher value than that from the method of averaging RH first (obtaining RH at low resolution) and then calculating AOT.

To further investigate where the AOT is most sensitive to the change in the RH horizontal resolution, we averaged the AOT differences over every $10^{\circ}$ of latitude using the entire year simulation. The corresponding relative and absolute changes of annually averaged zonal mean AOT are shown in Fig. 5. A large AOT difference $(\sim 13-21 \%)$ occurs over the middle latitudes in the $\mathrm{NH}$, similar to what is shown in Fig. 4. The maximum change occurs at $50-60^{\circ} \mathrm{N}$ with a value of 0.03 , which is equivalent to $18 \%$ of the local mean AOT. There is a smaller peak of absolute AOT change over the SH storm track $\left(40-65^{\circ} \mathrm{S}\right)$ which is dominated by high hydroscopic sea salt particles. The months when zonal mean AOT change reaches its maximum or minimum values during the year are also calculated, but no patterns were identified.
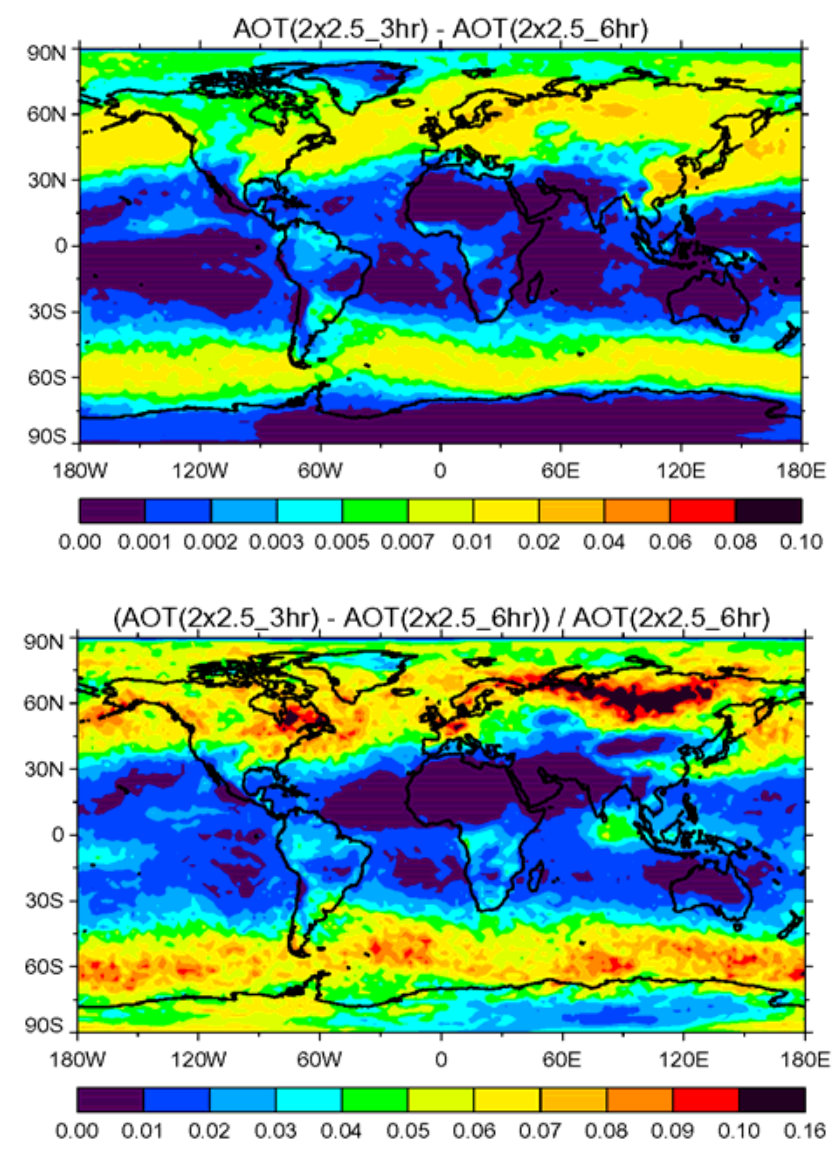

Fig. 6. Similar to Fig. 4, but with RH averaged over 3-h instead of 6-h intervals (note scale difference with Fig. 4).

Also shown in Fig. 5 are the differences over three major pollution regions: the Eastern US (A), Western Europe (E), and Eastern China (C). The large AOT change in these regions (16-20\%) reflects the strongly hygroscopic properties of the sulfate aerosols in polluted air.

The higher horizontal resolution simulation, HSHT, was compared to AERONET data in an analysis similar to that shown in Fig. 3. The correlation coefficient for the HSHT simulation is the same as that of LSHT, but the relative bias (B) of AOTs between the model and AERONET increases to 0.86 from 0.79 in the LSHT case. Thus, the comparison with AERONET provides evidence that increasing the horizontal resolution improves the model performance in this case.

\subsection{The effect of the change in RH temporal resolution on AOT}

The monthly AOT difference between the simulations with $\mathrm{RH}$ averaged over 3-h and 6-h temporal resolutions in April 2001 is shown in Fig. 6 with absolute difference [AOT(LSHT)-AOT(LSLT)] in the upper panel and relative difference [(AOT(LSHT)-AOT(LSLT))/AOT(LSLT)] in the 

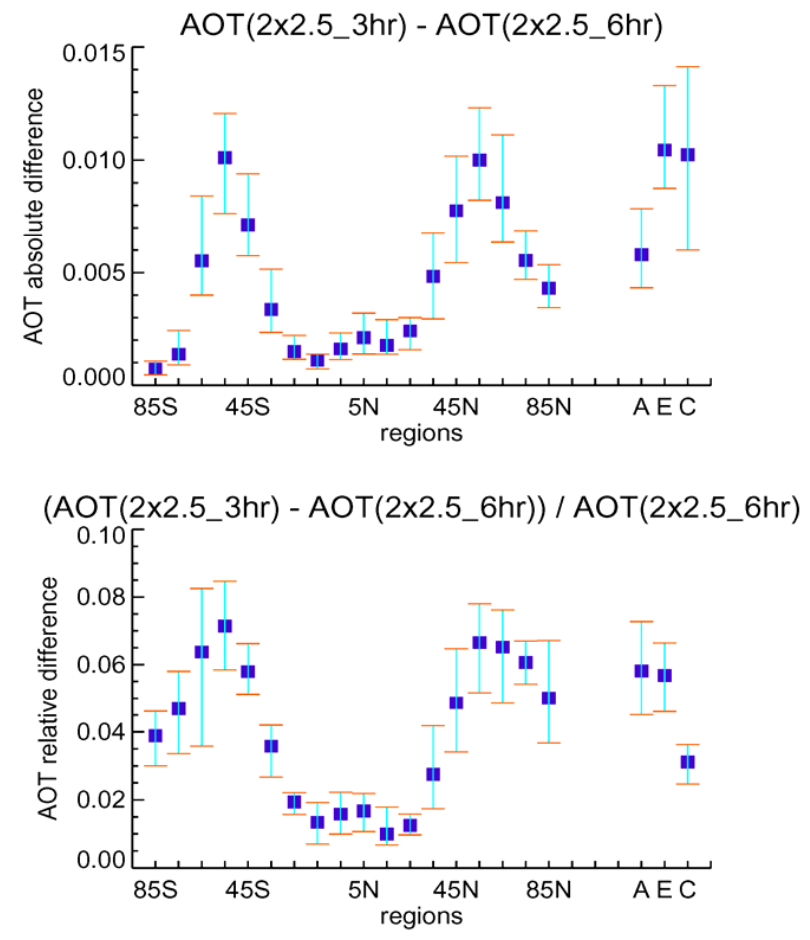

Fig. 7. Similar to Fig. 5, but for the change of RH temporal resolution.

lower panel. Similar to Fig. 4, AOT increases with the increase of RH resolution. This increase is largest over the NH mid-latitudes and the SH storm track. There is no significant AOT change over high mountainous regions (Fig. 6). The figure also shows that the regions dominated by dust usually have the smallest AOT change.

Figure 7 shows the zonally averaged differences in the AOT with the change of RH temporal resolution, binned by $10^{\circ}$ latitude for 2001 . The magnitude of the AOT change attributed to the prescribed RH temporal resolution (Fig. 7) is less than half of that attributed to RH spatial resolution (Fig. 5), however, the former AOT change may not be trivial considering that there is a factor of 2 change in temporal resolution while there a factor of 4 change in the spatial resolution. The maximum zonal mean AOT changes, 0.012 (absolute) and 6-8\% (relative), occur over the middle latitudes in both hemispheres. Unlike the case with varying RH spatial resolution, the maximum AOT change due to $\mathrm{RH}$ temporal resolution shows a seasonal pattern. In the $\mathrm{SH}$, the maximum difference occurs during late austral winter and early austral spring, while in the $\mathrm{NH}$, it occurs during the late boreal fall and ends in spring. The three regions with high industrial pollution again show high AOT changes, similar to Fig. 5.
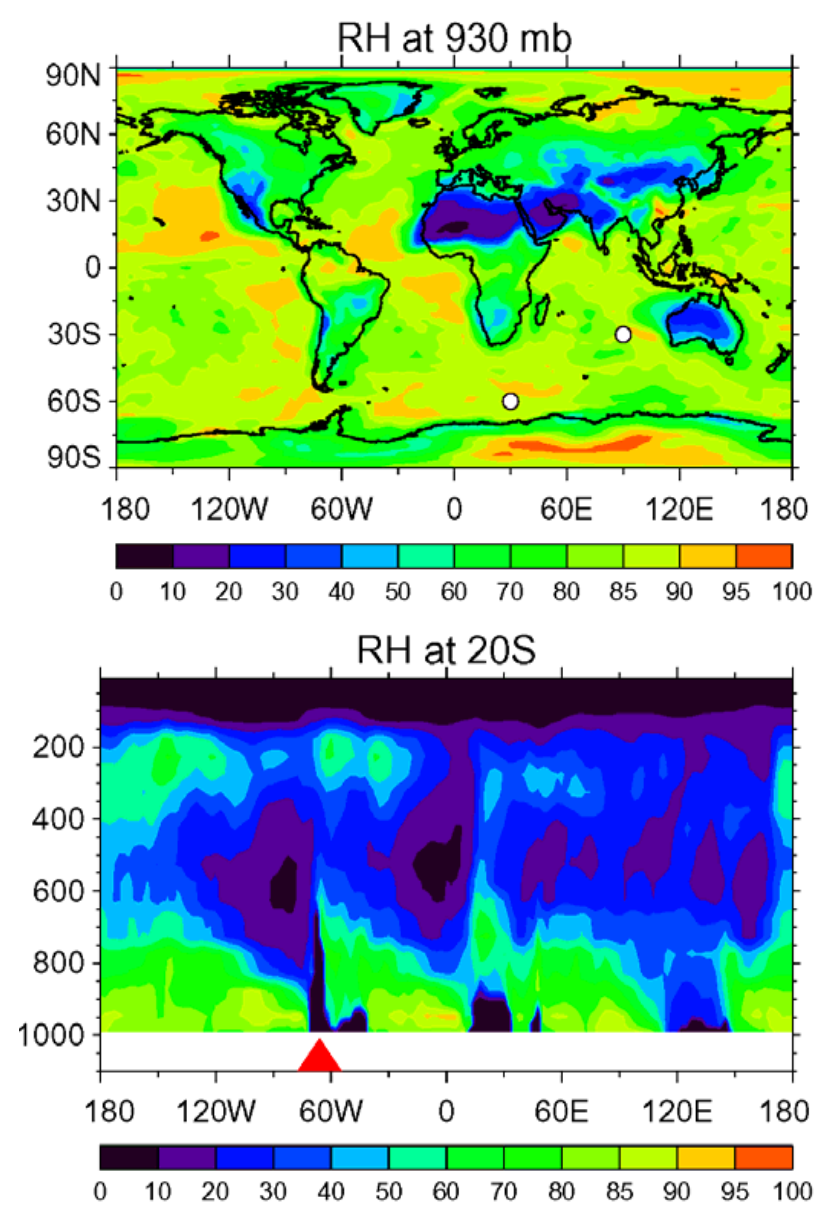

Fig. 8. Global RH field for April 2001 at $930 \mathrm{mb}$ (upper panel). Detailed RH change over two oceanic sites (white circles) is shown in Fig. 9. The lower panel shows vertical-longitude RH $\left(2 \times 2.5 \_3 \mathrm{hr}\right)$ distribution at latitude $20^{\circ} \mathrm{S}$ for April 2001. The Andes Mountains, located near longitudes $60^{\circ}-70^{\circ} \mathrm{W}$, are indicated by a red triangle.

\subsection{Factors controlling the variation of AOT with RH resolution}

The nonlinearity in the MEE-RH relationships shown in Fig. 1 suggests that RH magnitude, variation, and aerosol composition may influence the response of AOT to changing RH resolution. The RH magnitude may influence the response in two ways. At RH below $80 \%$, AOT is insensitive to the change of RH, while at $\mathrm{RH}$ above $80 \%$, the AOT response to a given RH change increases rapidly with increasing RH. The impact of low RH can be easily observed by matching the land areas of very low AOT change (Figs. 4 and 6) with the areas of low RH shown on the RH horizontal distribution at $930 \mathrm{mb}$ in Fig. 8 (upper panel). Over desert areas, hydrophobic particles dominate, AOT usually does not change. However, the impact of high RH is hard to discern from the figures without an understanding of aerosol components. 
It is relatively easy to understand that the larger the $\mathrm{RH}$ spatial/temporal variation is, the larger the AOT change will be when there is a change in RH spatial/temporal resolution. Figs. 4 and 8 (lower panel) show how spatial variations seen with different RH resolutions affect changes in AOT. The vertical distribution of $\mathrm{RH}$ at $20^{\circ} \mathrm{S}$ for April 2001 shows a break in the RH over the Andes Mountains around longitudes $60^{\circ}-70^{\circ} \mathrm{W}$. Accordingly, the maximum relative AOT change over the mountain area can be more than 200\% (Fig. 4 lower panel). Such regions require a high RH resolution in a CTM regardless of how good the underlying GCM calculation is. A similar example, but with RH temporal variation, is shown in Fig. 9, which describes, at two oceanic sites, the $3 \mathrm{~h} \mathrm{RH}$ change in April 2001 (upper panel), the aerosol mass and AOT of each aerosol component (middle panel), and the relative contribution of each component (lower panel). The two sites have a similar monthly mean RH at $930 \mathrm{mb}, 86.6 \%$ for a site in the Indian Ocean in $\mathrm{SH}$ middle latitude (I: $90^{\circ} \mathrm{E}$, $30^{\circ} \mathrm{S}$ ) and $87.6 \%$ for a site within the SH storm track (S: $30^{\circ} \mathrm{E}, 60^{\circ} \mathrm{S}$ ) (white circles in Fig. 8 upper panel). However, $\mathrm{RH}$ temporal change at site $\mathrm{S}$ is significantly higher than that at site I (Fig. 9 upper panel). In such cases, the AOT change in site $\mathrm{S}$ would be larger than that in site I. This is confirmed by the calculated sulfate masses and their AOTs at the two sites. The sulfate mass at site $\mathrm{S}$ is only half of that at $\mathrm{I}$, but sulfate AOT at $\mathrm{S}$, on the other hand, is $28 \%$ higher than that at I (Fig. 9, middle pane).

Aerosol components, which usually have different MEERH relationships, impose another constraint on the simulated AOT change with the change of RH resolution. For example, sulfate AOT will be much more enhanced than that of sea salt at high RH (Fig. 1). This is evident in Fig. 9, lower panel, which shows that the fraction of sulfate mass at $\mathrm{S}(2.2 \%)$ is less than a quarter of that at I $(9.2 \%)$, while the sulfate AOT at site S $(24.7 \%)$ is more than half of that at I (45.6\%).

Our study indicates that if a RH field is used in a coarser resolution (in our case, spatially from $1^{\circ} \times 1.25^{\circ}$ to $2^{\circ} \times 2.5^{\circ}$ or temporally from $3 \mathrm{~h}$ average to $6 \mathrm{~h}$ average), the simulated AOT will be reduced although the RHs would have the same values when averaged at the same spatial and temporal scales. Of course, the effect of RH field on the variation of AOT is a broad issue. One other possible effect is that the higher resolution RH field itself may be subject to a large uncertainty due to the different treatments used in a GCM. The spatial and temporal variability of RH might be very different even if the GCM resolution is the same. For instance, RH variability might be higher in a free running GCM than in reanalysed RH fields as used in this study.

In addition to MEE (and AOT) uncertainty due to the subgrid RH variation, the aerosol MEE could also vary significantly at any given RH. For example, measurements during recent field campaigns indicated that, compared to the value of dry $(\mathrm{RH} \leq 40 \%)$ sulfate particles, the sulfate MEE at RH $85 \%$ was enhanced by about 3.5 times for ACEAsia, 3.0 for ICARTT, and 2.0 for INDOEX (Quinn et al., 2005).

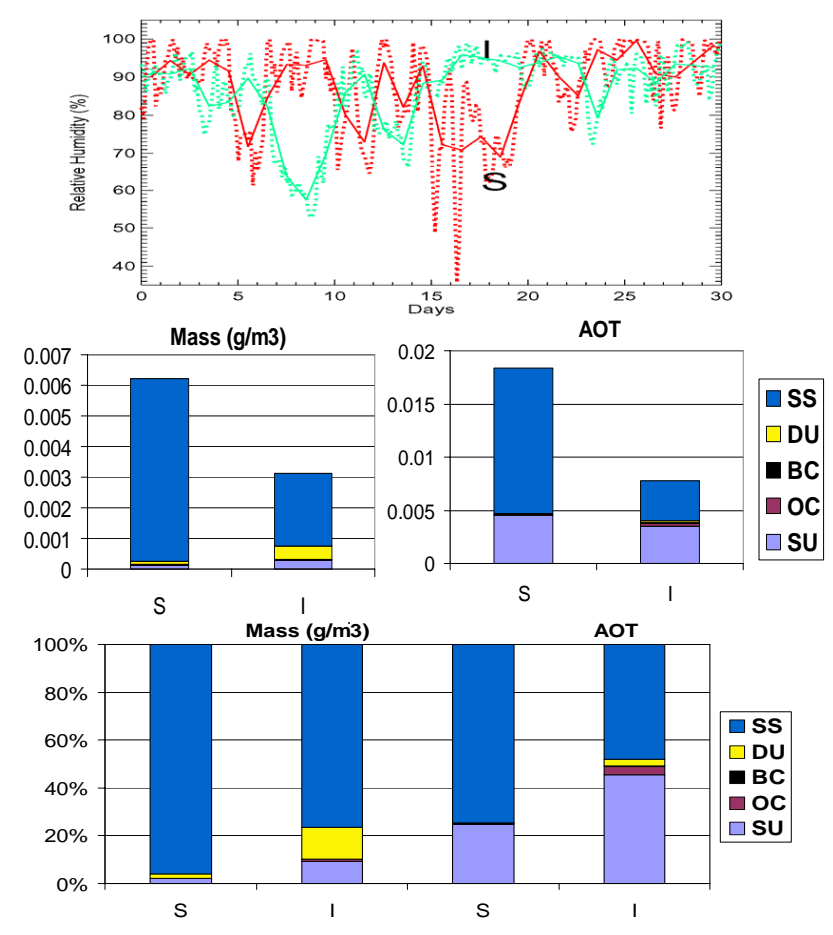

Fig. 9. Upper panel: RH at $930 \mathrm{mb}$ in April 2001 at two ocean sites $\mathrm{S}\left(\right.$ red, $30^{\circ} \mathrm{E} 60^{\circ} \mathrm{S}$ ) and I (green, $90^{\circ} \mathrm{E} 30^{\circ} \mathrm{S}$ ); see also the white circles in Fig. 8 upper panel. The solid lines represent daily mean and dotted lines are 3-h averages. Middle panel: Monthly averaged aerosol masses (left) and AOTs (right) for each aerosol component at ocean sites S and I. Lower panel: the fraction of aerosol mass and AOT from each aerosol component, e.g. SU (sulfate), DU (dust), BC (black carbon), OC (organic carbon), and SS (sea salt).

The value was 3.3 in our model. Part of the reason for such a large MEE uncertainty at RH $85 \%$ may be the different aerosol heritages in the different environments. Currently, most global/regional models parameterize aerosol size distribution and refractive index, which determine MEE through the Mie-theory, to be an empirical function of RH based on limited observations (Köpke et al., 1997; Chin et al., 2002). Clearly, this approach implies uncertainties in the growth calculation because (1) the fitting curve was frequently obtained from observational data that has a wide range, and (2) the sampled observations may not fully represent the complexity of atmospheric processes due to different aerosol composition and the heritage of the particles (i.e. deliquescence and crystallization) (Jordanov and Zellner, 2006; Pant et al., 2006; Chan et al., 2006; Semeniuk et al., 2007).

\subsection{The effect of the change in RH on the aerosol DRE}

To understand the importance of the sub-grid scale change in RH on aerosol radiative forcing, we analyzed here the change of aerosol TOA DRE $\left(\mathrm{Wm}^{-2}\right)$ from the different RH resolutions. We applied the radiation code described in Sect. 2.2 
Table 3. The aerosol TOA DREs of the three experiments and the percentage changes of the aerosol DREs between the two different horizontal resolution cases and the two different temporal resolution cases

\begin{tabular}{llrrrrrrrrr}
\hline & & \multicolumn{3}{c}{ Ocean } & \multicolumn{3}{c}{ Land } & \multicolumn{3}{c}{ Global } \\
& & LSHT & HSHT & LSLT & LSHT & HSHT & LSLT & LSHT & HSHT & LSLT \\
\hline \multirow{2}{*}{ clear sky } & DRE $\left(\mathrm{W} / \mathrm{m}^{2}\right)$ & -4.4 & -4.8 & -4.2 & -8.4 & -9.1 & -8.3 & -5.6 & -6.1 & -5.4 \\
& $\mathrm{dDRE} *(\%)$ & & 8.9 & 3.5 & & 8.0 & 2.1 & & 8.4 & 2.9 \\
\multirow{5}{*}{ whole sky } & DRE $\left(\mathrm{W} / \mathrm{m}^{2}\right)$ & -3.3 & -3.6 & -3.2 & -6.9 & -7.4 & -6.8 & -4.4 & -4.8 & -4.3 \\
& $\mathrm{dDRE}(\%)$ & & 9.3 & 3.1 & & 7.7 & 1.9 & & 8.5 & 2.6 \\
\hline
\end{tabular}

* dDRE (HSHT) $=[$ AOT (HSHT)-AOT (LSHT)]/AOT (LSHT)

dDRE (LSLT) $=[$ AOT (LSHT)-AOT (LSLT)]/AOT (LSLT)

to calculate DREs with and without aerosols. The difference between them is aerosol DRE. We repeated such calculations with the AOT, $\omega$, and g obtained from different spatial and temporal resolutions of $\mathrm{RH}$, as described in Sect. 3.1 to 3.3.

The aerosol TOA DREs of the three experiments are given in Table 3. The data were averaged over ocean, land, and global areas for clear sky and whole sky. The percentage changes of the aerosol DREs between the two different horizontal resolution cases and the two different temporal resolution cases are also listed in the table.

In the LSHT, clear sky aerosol DRE at TOA over oceans is $-4.4 \mathrm{~W} / \mathrm{m}^{2}$, comparable to other estimates. For example, Yu et al. (2006) estimated this value to be $-4.1 \mathrm{~W} / \mathrm{m}^{2}$ with a GOCART model simulation, $-5.9 \mathrm{~W} / \mathrm{m}^{2}$ using the data of MODIS, and $-5.5 \mathrm{~W} / \mathrm{m}^{2}$ with the data combining Clouds and the Earth's Energy System (CERES) radiances with aerosol properties from the MODIS level 2 daily aerosol retrievals at a resolution of $10 \mathrm{~km}$. Zhang et al. (2005) estimated this value to be $-5.3 \pm 1.7 \mathrm{~W} / \mathrm{m}^{2}$ using aerosol and cloud data from CERES and MODIS. Over land, however, the aerosol clear sky DRE $\left(-8.4 \mathrm{~W} / \mathrm{m}^{2}\right)$ given by the LSHT study is much higher than the estimates of Patadia et al. (2008) $\left(-5.1 \pm 1.14 \mathrm{~W} / \mathrm{m}^{2}\right)$ and $\mathrm{Yu}$ et al. (2006) $\left(-4.5 \pm 0.4 \mathrm{~W} / \mathrm{m}^{2}\right)$. Analysis of speciation contribution indicated that about half of the land aerosol DRE $\left(-3.9 \mathrm{~W} / \mathrm{m}^{2}\right)$ comes from the dust particles.

The clear sky aerosol cooling effect is enhanced by $8.9 \%$ (ocean), $8.0 \%$ (land), and $8.4 \%$ (global) when the RH horizontal resolution is increased from $2^{\circ} \times 2.5^{\circ}$ to $1^{\circ} \times 1.25^{\circ}$. A slightly higher variation over oceans comes from the fact that the ocean aerosol DRE is dominated by the hydrophilic species sea salt ( $1 / 3$ of total) and anthropogenic particles ( $1 / 3$ of total) with dust $(\sim 8 \%)$ and the other nature aerosols contributing to the rest, while the land DRE is dominated by both anthropogenic particles (1/3 of total) and hydrophobic dust particles $(\sim 1 / 2$ of total) with a small fraction from sea salt $(\sim 3 \%)$ and other natural aerosols. The aerosol cooling effect is reduced by $20-25 \%$ from the clear sky to the whole sky calculation; however, the changes of aerosol TOA DRE due to the changes of RH horizontal resolution in both cal- culations are comparable. The change of aerosol TOA DRE due to the change of RH temporal resolution is only about $1 / 3$ of that due to the change of RH horizontal resolution in both calculations (the magnitude of RH temporal resolution change is only half of that in spatial resolution change). Regionally, the change in the aerosol TOA DRE is higher over the middle latitudes of both hemispheres, similar to the pattern of the AOT change.

Considering anthropogenic aerosols alone, the whole sky TOA DREs would be -2.48 (land), -0.95 (ocean), and -1.41 (global) for the LSHT study and the cooling effects are enhanced to be $-3.33 /-1.26 /-1.86$, respectively in the clear sky calculation. The influence of anthropogenic aerosols on DRE was calculated by differencing the DRE from all aerosols with the DRE with only natural aerosols. The changes of the TOA DREs due to different spatial resolutions are $16.9 \% / 13.7 \% / 15.1 \%$ for the whole sky and $15.6 \% / 12.7 \% / 14.9 \%$ for the clear sky calculations. These changes are larger than those contributed from all aerosols even over oceans where sea salt is a major aerosol component. This behavior can be confirmed from Fig. 1 which shows that the sensitivity of MEE to RH is much higher for anthropogenic aerosols than for sea-salt aerosols.

The change of aerosol TOA DRE due to the change of the $\mathrm{RH}$ resolutions is not large considering that there is a wide range of aerosol DRE estimates from the literature based on measurements and model simulations. Nevertheless, the change is systematic: the higher the resolution, the more negative the TOA DRE (i.e. the larger the aerosol cooling effect).

\section{Conclusions}

We investigated the impacts of using RHs representing different spatial and temporal resolutions on AOT and aerosol TOA DRE simulations. The three RH resolutions used in the study represent current commonly used model resolutions. One firm conclusion is that AOT and the aerosol cooling effect always increase with an increase in the RH resolution. On a global basis, the AOT increases by $11 \%$ with the higher 
spatial resolution and $4 \%$ with the higher temporal resolution. Correspondingly, the aerosol cooling effect (i.e. the magnitude of the negative value of TOA DRE) increases by 9\% and 3\% for a use of the higher spatial and temporal resolution respectively. The anthropogenic aerosol cooling effect of the finer spatial resolution is even higher at $15 \%$ for both clear and whole skies because the sensitivity of MEE to RH is much higher for anthropogenic aerosols than for sea-salt aerosols. On a regional scale, the impact of finer RH spatial resolution on AOT change can be much larger. The AOT increases by more than $20 \%$ over Western Europe and eastern North America (note that the AOT itself is also higher over these regions) and could increase by more than a factor of 2 over the Andes Mountains. Overall, the AOT change is larger in middle latitudes than in tropical regions, largely because of the larger contribution of hydrophobic dust in tropical regions.

Two features of the RH field, its magnitude and variation, constrained by aerosol components, determine where and when AOT is most sensitive to RH. Over low RH regions, such as deserts, AOT is insensitive to the choice of RH resolution due to both the aerosol composition (dust dominated) and aerosol optical property (small MEE change even for hygroscopic aerosols) in such regions. Over high RH regions, such as over most oceans, Europe, and the east coasts of continents, the importance of relative humidity (RH) on aerosol optical thickness (AOT) is substantially amplified because of hygroscopicity of aerosols in these regions. It is worth pointing out that a host model in which a specific aerosol module is embedded may react differently to the same meteorological fields and thus affect the relationship between RH and AOT.

Our study indicates that the simulated AOT is sensitive to the RH resolution. Two questions raised here are whether the AOT continues to increase when the RH resolution is increased, and whether a "best" resolution can be determined that represents a promise between accuracy and model efficiency. Instinctively, we think that such a resolution can be found because the sensitivity of the AOT will decline as the spatial (or temporal) heterogeneity of RH between grid boxes (or over an averaged period) lessens as the resolution increases. The resolution required for adequate accuracy likely depends on region. Our results indicate that the middle latitudes of both hemispheres tend to require a higher resolution than tropical regions in order to have the same AOT variation when $\mathrm{RH}$ resolution varies.

Our study indicates that the diversity among the AOT annual global means (i.e. 0.065-0.151) from 20 different models in an AeroCom AOT study (Kinne et al., 2006) could be partially attributed to the differences in model resolutions, since the RH resolutions of the participating models change about 186 times (i.e. from $1.1^{\circ}$ (latitude) $\times 1.1$-(longitude) to $\left.10^{\circ}-22.5^{\circ}\right)$. Of course, other chemical and physical processes also contribute to the diversity (Textor et al., 2006). Nevertheless, one way to improve the performance of a sys- tem is to better understand and quantify the role of each process. The key conclusion of this paper is that increasing RH resolution increases the simulated AOT (and aerosol cooling effect). In other words, a high resolution model should have a larger, more realistic AOT simulation than a low resolution model. If it does not (very likely due to the complexity of the system), then further investigation is required. In the AeroCom comparisons, we need to bear this in mind.

The magnitude of the AOT variation associated with the $\mathrm{RH}$ resolution is subject to several limitations in the model's ability to resolve aerosol microphysical processes in the real atmosphere (Haywood et al., 1997; Ghan and Easter, 1998). Exploration of the activation of aerosol particles in cloudy regions is beyond the scope of this study.

Acknowledgements. The authors wish to acknowledge the assistance of Arlindo da Silva in understanding $\mathrm{RH}$ distributions in the GEOS-4 system and the three reviewers whose comments improved the manuscript. This work was supported by the NASA Atmospheric Chemistry Modeling and Analysis Program.

Edited by: A. Nenes

\section{References}

Bloom, S., da Silva, A., Dee, D., Bosilovich, M., Chern, J.-D., et al.: Documentation and Validation of the Goddard Earth Observing System (GEOS), Data Assimilation System-Version 4, NASA/TM-2005-104606, Vol. 26, 2005.

Chan, M. N., Lee, A. K. Y., and Chan, C. K.: Responses of ammonium sulfate particles coated with glutaric acid to cyclic changes in relative humidity: Hygroscopicity and Raman characterization, Environ. Sci. Technol., 40(22), 6983-6989, 2006.

Chin, M., Ginoux, P., Holben, B. N., Chou, M.-D., Kinne, S., and Weaver, C.: The GOCART model study of aerosol composition and radiative forcing, paper presented at 12th Symposium on Global Change and Climate Variations, Am. Meteorol., Soc., Albuquerque, New Mexico, 2001.

Chin, M., Ginoux, P., Kinne, S., Torres, O., Holben, B. N. , Duncan, B. N., et al.: Tropospheric aerosol optical thickness from the GOCART model and comparisons with satellite and sun photometer measurements, J. Atmos. Sci., 59, 461-483, 2002.

Chin, M., Chu, A., Levy, R., Remer, L., Kaufman, Y., Holben, B., Eck, T., Ginoux, P., and Gao Q.: Aerosol distribution in the northern hemisphere during ACE-Asia: Results from global model, satellite observations, and sunphotometer measurements, J. Geophys Res., 109, D23S90, doi:10.1029/2004JD004829, 2004.

Chou, M.-D. and Suarez, M. J.: A solar radiation parameterization for atmospheric studies, Technical Report Series on Global Modeling and Data Assimilation, NASA Tech. Memo., 104606, 15, 40 pp., 1999.

Christopher, S. A., and Zhang, J.: Shortwave aerosol radiative forcing from MODIS and CERES observations over the oceans, Geophys. Res. Lett., 29, 1859, doi:10.1029/2002GL014803, 2002.

Considine, D. B., Connell, P.S., Bergmann, D. J., Rotman, D. A., and Strahan, S. E., Sensitivity of Global Modeling 
Initiative model predictions of Antarctic ozone recovery to input meteorological fields, J. Geophys. Res., 109, D15301, doi:10.1029/2003JD004487, 2004.

Douglass, A. R., Connell, P. S., Stolarski, R. S., and Strahan, S. E.: Radicals and reservoirs in the GMI chemistry and transport model: comparison to measurements, J. Geophys. Res., 109, D16302, doi:10.1029/2004JD004632, 2004.

Fishman, J., Wozniak, A. E., and Creilson, J. K.: Global distribution of tropospheric ozone from satellite measurements using the empirically corrected tropospheric ozone residual technique: Identification of the regional aspects of air pollution, Atmos. Chem. Phys., 3, 893-907, 2003, http://www.atmos-chem-phys.net/3/893/2003/.

Ghan, S., and Easter, R. C.: Comments on "A limited-area-model case study of the effects of sub-grid scale variation in relative humidity and cloud upon the direct radiative forcing of sulfate aerosol", Geophy. Res. Lett., 25(7), 1039-1040, 1998.

Ginoux, P., Chin, M., Tegen, I., Prospero, J. M., Holben, B., Dubovik, O., and S.-J. Lin: Sources and distributions of dust aerosols simulated with the GOCART model, J. Geophys. Res., 106(D17), 20255-20273, 2001.

Gong, S., Barrie, L. A., and J.-P. Blanchet: Modeling sea salt aerosols in the atmosphere, 1: Model development, J. Geophys. Res., 102, 3805-1818, 1997.

Haywood, J. M., V. Ramaswany, and L. J. Donner, A limited-areamodel case study of the effects of sub-grid scale variation in relative humidity and cloud upon the direct radiative forcing of sulfate aerosol, Geophy.Res. Lett., 24(2), 143-146, 1997.

Hess, M., P. Köpke, and Schult, I.: Optical Properties of Aerosols and Clouds: The Software Package OPAC, B Am. Meteorol. Soc., 79(5), 831-844, doi:10.1175/1520-0477, 1998.

Intergovernmental Panel on Climate Change (IPCC), Climate Change 2001: Synthesis Report: Third Assessment Report of the Intergovernmental Panel on Climate Change, Cambridge University Press, New York, 289-348, 2001.

Jordanov, N., and Zekkberm, R.: Investigations of the hygroscopic properties of ammonium sulfate and mixed ammonium sulfate and glutaric acid micro droplets by means of optical levitation and Raman spectroscopy, Phy. Chem. Chem. Phy., 8(23), 27592764, 2006.

Kinne, S., Schulz, M., Textor, C., Guibert, S., Balkanski, Y., Bauer, S. E., Berntsen, T., Berglen, T. F., Boucher, O., Chin, M., Collins, W., Dentener, F., Diehl, T., Easter, R., Feichter, J., Fillmore, D., Ghan, S., Ginoux, P., Gong, S., Grini, A., Hendricks, J., Herzog, M., Horowitz, L., Isaksen, I., Iversen, T., Kirkevåg, A., Kloster, S., Koch, D., Kristjansson, J. E., Krol, M., Lauer, A., Lamarque, J. F., Lesins, G., Liu, X., Lohmann, U., Montanaro, V., Myhre, G., Penner, J., Pitari, G., Reddy, S., Seland, O., Stier, P., Takemura, T., and Tie, X.: An AeroCom initial assessment - optical properties in aerosol component modules of global models, Atmos. Chem. Phys., 6, 1815-1834, 2006,

http://www.atmos-chem-phys.net/6/1815/2006/.

Liu, X., Penner, J. E., Das, B., et al.: Uncertainties in global aerosol simulations: Assessment using three meteorological datasets, J. Geophys. Res., 112, D11212, doi:10.1029/2006JD008216, 2007.

Logan, J. A.: An analysis of ozonesonde data for the troposphere: Recommendations for testing 3-D models, and development of a gridded climatology for tropospheric ozone, J. Geophys. Res., 104, 16, 115-16, 149, 1999.
Malm, W. C., Day, D. E., Kreidenweis, S. M., Collett, J. L., Carrico, C., McMeeking, G., and Lee, T.: Hygroscopic properties of an organic-laden aerosol, Atmos. Environ., 39 (27), 4969-4982, 2005.

Monahan, E. C., Spiel, D. E., and Davidson, K. L.: A model of marine aerosol generation via whitecaps and wave disruption, in: Oceanic Witecaps, edited by: Monahan, E. C. and Mac Niocaill, G., Dordrecht, Reidel, 167-174, 1986.

Pahlow, M., Feingold, G., Jefferson, A., Andrews, E., Ogren, J. A., Wang, J., Lee, Y. N., Ferrare, R. A., and Turner, D. D.: Comparison between lidar and nephelometer measurements of aerosol hygroscopicity at the Southern Great Plains Atmospheric Radiation Measurement site, J. Geophy. Res., 111(D5), D05S15, doi:10.1029/2004JD005646, 2006.

Pant, A., Parsons, M. T., and Bertram, A. K.: Crystallization of aqueous ammonium sulfate particles internally mixed with soot and kaolinite: Crystallization relative humidities and nucleation rates, J. Phys. Chem. A., 110(28), 8701-8709, 2005.

Patadia, F., Gupta, P., and Christopher, S. A.: First estimates of global shortwave aerosol direct radiative effect over land using merged CERES, MODIS and MISR data, Geophys. Res. Lett., 35, L04810, doi:10.1029/2007GL032314, 2008.

Penner, J. E., Chuang, C., and Grant, K.: Climate forcing by carbonaceous and sulfate aerosols, Climate Dynamics, 14, 839-851, 1998.

Quinn, P. K., Bates, T. S., Baynard, Clarke, A. D., Onasch, T. B., Wang, W., Rood, M. J., Andrews, E., Allan, J., Carrico, C. M., Coffiman, D., and Worsnop, D.: Impact of particulate organic matter on the relative humidity dependence of light scattering: A simplified parameterization, Geophys. Res. Lett., 32, L22809, doi:10.1029/2005GL024322, 2005.

Semeniuk, T. A., Wise, M. E., Martin, S. T., Russell, M., and Buseck, P. R.: Hygroscopic behavior of aerosol particles from biomass fires using environmental transmission electron microscopy, J. Atmos. Chem., 56(3), 259-273, 2007,

Schulz, M., Textor, C., Kinne, S., Balkanski, Y., Bauer, S., Berntsen, T., Berglen, T., Boucher, O., Dentener, F., Guibert, S., Isaksen, I. S. A., Iversen, T., Koch, D., Kirkevåg, A., Liu, X., Montanaro, V., Myhre, G., Penner, J. E., Pitari, G., Reddy, S., Seland, Ø., Stier, P., and Takemura, T.: Radiative forcing by aerosols as derived from the AeroCom present-day and pre-industrial simulations, Atmos. Chem. Phys., 6, 5225-5246, 2006, http://www.atmos-chem-phys.net/6/5225/2006/.

Strahan, S. E. and A. R. Douglass: Evaluating the credibility of transport processes in simulations of ozone recovery using the Global Modeling Initiative three-dimensional model, J. Geophys. Res., 109, D05110, doi:10.1029/2003JD004238, 2004.

Strahan, S. E., Duncan, B. N., and Hoor, P.: Observationally derived transport diagnostics for the lowermost stratosphere and their application to the GMI chemistry and transport model, Atmos. Chem. Phys. Discuss., 7, 1449-1477, 2007, http://www.atmos-chem-phys-discuss.net/7/1449/2007/.

Textor, C., Schulz, M., Guibert, S., Kinne, S., Balkanski, Y., Bauer, S., Berntsen, T., Berglen, T., Boucher, O., Chin, M., Dentener, F., Diehl, T., Easter, R., Feichter, H., Fillmore, D., Ghan, S., Ginoux, P., Gong, S., Grini, A., Hendricks, J., Horowitz, L., Huang, P., Isaksen, I., Iversen, I., Kloster, S., Koch, D., Kirkevåg, A., Kristjansson, J. E., Krol, M., Lauer, A., Lamarque, J. F., Liu, X., 
Montanaro, V., Myhre, G., Penner, J., Pitari, G., Reddy, S., Seland, Ø., Stier, P., Takemura, T., and Tie, X.: Analysis and quantification of the diversities of aerosol life cycles within AeroCom, Atmos. Chem. Phys., 6, 1777-1813, 2006, http://www.atmos-chem-phys.net/6/1777/2006/.

Wang, J., Jacob, D. J., and Martin, S. T.: Sensitivity of sulfate direct climate forcing to the hysteresis of particle phase transitions, J. Geophys. Res., 113, D11207, doi:11210.11029/12007JD009368, 2008.

Weaver, C. J., Ginoux, P., Hsu, N. C., Chou, M.-D., and J. Joiner: Radiative Forcing of Saharan Dust: GOCART model simulations Compared with ERBE data, J. Atmos. Sci., 59(3), 736-747, 2002.

Yoon, S. C., and J. Kim: Influences of relative humidity on aerosol optical properties and aerosol radiative forcing during ACE-Asia, Atmos. Environ., 40(23), 4328-4338, 2006.
Yu, H., Kaufman, Y. J., Chin, M., Feingold, G., Remer, L. A., Anderson, T. L., Balkanski, Y., Bellouin, N., Boucher, O., Christopher, S., DeCola, P., Kahn, R., Koch, D., Loeb, N., Reddy, M. S., Schulz, M., Takemura, T., and Zhou, M.: A review of measurement-based assessments of the aerosol direct radiative effect and forcing, Atmos. Chem. Phys., 6, 613-666, 2006, http://www.atmos-chem-phys.net/6/613/2006/.

Zhang, J., Christopher, S. A., Remer, L. A., and Kaufman, Y. J.: Shortwave aerosol radiative forcing over cloud-free oceans from Terra: 2. Seasonal and global distribution, J. Geophy. Res., 110, D10S24, doi:10.1029/2004JD005009, 2005. 